\title{
Syndromic surveillance of female sexually transmitted infections in primary care: a descriptive study in Monastir, Tunisia, 2007-2017
}

Wafa Dhouib ${ }^{1 *}$ (D) Imen Zemni ${ }^{1}$, Meriem Kacem ${ }^{1}$, Cyrine Bennasrallah ${ }^{1}$, Manel Ben Fredj ${ }^{1}$, Hela Abroug $^{1}$, Samia Grira², Maha Mastouri ${ }^{3}$ and Asma Sriha Belguith ${ }^{1}$

\begin{abstract}
Background: Sexually Transmitted Infections (STIs) are a public health problem, especially for reproductive-age women. The aim of this study was to determine the incidence and trend of STIs during 11 years in Tunisia (200717).

Methods: We conducted a descriptive study including all women with curable STls (chlamydia, gonorrhea, syphilis and trichomoniasis) diagnosed with the syndromic approach in all basic health care centers of the Governorate of Monastir (Tunisia) from 2007 to 2017. Syndromes included, Pelvic Pain (PP), Vaginal Discharge (VD) and Genital Ulceration (GU).

Results: We analyzed 40,388 episodes of curable STIs with a crude incidence rate and age standardized incidence rate of 1393 (95\% Confidence Interval (Cl); 1348-1438) / 100,000 Person Year (PY) and 1328 (95\%Cl; 1284-1372) /100,000 PY respectively. The incidence rate showed a positive trend over 11 years for all age groups and syndromes. VD was the most common syndrome with a crude incidence rate of 1170/100,000 PY. For all syndromes, women aged 20 to 39 were the most affected age group $(p<0.001)$.
\end{abstract}

Conclusion: In conclusion, the incidence rate of STIs episodes among women diagnosed with the syndromic approach was high, consistent with the global evidence. Focusing on reviewing STIs surveillance system in low and middle-income countries could allow the achievement of the ending of STIs epidemics by 2030.

Keywords: Sexually transmitted diseases, Vaginal discharge, C. trachomatis, Neisseria gonorrhoeae, Syphilis, Trichomonas vaginalis, Gardnerella vaginalis

\section{Background}

Around the world, Sexually Transmitted Infections (STIs) are a public health problem being one of the leading causes of morbidity and mortality. World Health Organization's (WHO) 2012 and 2016 estimates of the

\footnotetext{
* Correspondence: wafa.dhouib20@yahoo.fr

${ }^{1}$ Department of Epidemiology and Preventive Medicine, University of Monastir, Monastir, Tunisia

Full list of author information is available at the end of the article
}

global prevalence and incidence of curable STIs (chlamydia, gonorrhoea, trichomoniasis, and syphilis) in adults remain high, with nearly one million new infections each day $[1,2]$. The spread of STIs leads to many sequelae and complications that disproportionately affect women and adolescents [3-5]. WHO implemented the first (2006-2015) and the second (2016-2021) strategy on STIs with the goal of ending STIs epidemics as a public health concerns by $2030[6,7]$. In general, low- and

(c) The Author(s). 2021 Open Access This article is licensed under a Creative Commons Attribution 4.0 International License, which permits use, sharing, adaptation, distribution and reproduction in any medium or format, as long as you give appropriate credit to the original author(s) and the source, provide a link to the Creative Commons licence, and indicate if changes were made. The images or other third party material in this article are included in the article's Creative Commons licence, unless indicated otherwise in a credit line to the material. If material is not included in the article's Creative Commons licence and your intended use is not permitted by statutory regulation or exceeds the permitted use, you will need to obtain permission directly from the copyright holder. To view a copy of this licence, visit http://creativecommons.org/licenses/by/4.0/. The Creative Commons Public Domain Dedication waiver (http://creativecommons.org/publicdomain/zero/1.0/) applies to the data made available in this article, unless otherwise stated in a credit line to the data. 
middle-income countries (LMICs) have higher estimated burdens of STIs than high-income countries (HICs) [2]. In these countries, STIs diagnostic tests are largely unavailable, expensive and technically demanding on microbiological surveillance systems, so that, surveillance of clinical syndromes called.

syndromic approach is easier to establish in public health. Although this approach according to the WHO guidelines obtains the highest marks in terms of development rigor with ongoing training every 2 years and is the surveillance system that can best represent the epidemiology of STIs in general population, they may result in an underestimated burden due to asymptomatic cases and have moderate specificity and sensitivity $[8,9]$.

In the Maghreb (region of North Africa bordering the Mediterranean Sea), some studies have focused on sex workers and women requesting abortion whose STI diagnostic criteria were based on laboratory results (endocervical, urine and vaginal sample) [10-13]. However, few studies have used clinical surveillance data to establish the trend and incidence of certain curable STIs in the general population $[14,15]$.

Quantifying the incidence of STIs is important for planning and promoting sexual health interventions. Thus, it is necessary to have current data to evaluate the situation in the Maghreb and more specifically in Tunisia to confirm the hypothesis of the decreasing number of STIs and to possibly reach the desired objective by WHO for 2030.

The aim of this study was to determine the incidence of symptomatic STIs among women during eleven-years in the governorate of Monastir and to evaluate the effectiveness of syndromic management approach to reach the $2030 \mathrm{WHO}$ goals.

\section{Methods}

We conducted a descriptive study including all female episodes of STIs from January 1, 2007 to December 31, 2017.

Monastir Governorate is one of the twenty-four governorates of Tunisia. It is situated in northeastern Tunisia. It covers an area of $1019 \mathrm{~km}^{2}\left(393 \mathrm{mi}^{2}\right)$ and is divided into thirteen delegations. In 2014, the population of Monastir represented $4.99 \%$ of the Tunisian population [16]. In 2015, the total number of Basic health centers (BHC) in the governorate of Monastir was 101 [17]. Primary care sectorization is regulated to provide treatment to people in their own region. Each BHC only receives patients who are geographically assigned to it. Therefore, each patient can only consult in one BHC except urgent cases.

Participants: From January 1, 2007 to December 31, 2017, we included all new episode of female STIs diagnosed and treated according to the WHO syndromic approach summarized in flowcharts (clinical algorithm) [18] (Appendix 1). A person with repeated infections may count more than once. The components of case management included: taking history, examination, correct diagnosis, early and effective treatment, advice on sexual behaviour, promotion and/or provision of condoms. All STIs cases diagnosed by the syndromic approach were registered by the physicians or midwifes of each $\mathrm{BHC}$ prospectively in a form that was reported to the regional direction of primary health at the end of each month and recorded on "epi-info" software.

All women in all age groups who consulted the midwives or physicians of each BHC in Monastir governorate for sexual health services and diagnosed by the syndromic approach from January 1, 2007 to December 31, 2017 were included in the study. Other STIs cases, which were not diagnosed by the syndromic approach such as vesicular lesions (herpes), chancroid and genital warts, were not included in this study. Patients who lived in other areas were excluded from the study.

Data included variables related to age, sex, consultation date and diagnosis.

The syndromic approach included four STIs presented clinically by four symptoms: Pelvic Pain (PP), Vaginal Discharge (VD), Genital Ulceration (GU) and Ureteral Discharge (UD).VD include cervicitis, vaginitis and vaginosis whose symptoms are respectively discharge of muco-pus through the cervix, smelly fluid vaginal discharge and non-specific vaginal discharge (thicker, greenish, smelly) [18]. For each syndrome, there are well-defined infectious agents incriminated in its symptomatology [18] (Table 1).

As data collection from the registry of STI surveillance was conducted retrospectively, data available on personal and contact information was not exhaustive and there could be a risk of under reporting.

Tunisian National Institute of Statistics provides each year the estimation of female population and their distribution by age and governorate [19].

The crude incidence rate (CIR) was calculated by dividing the total number of episodes from 2007 to 2017 in Monastir by eleven, and by the female population in Monastir then multiplied by 100,000 . It was expressed as the number per 100,000 person-years (/100,000 PY). $\mathrm{CIR}=\quad\left(\frac{\text { (total number of episodes })}{11}\right) /($ the average female population) $) * 100000$. The average population was calculated as follows: ((the sum of estimated female population each year) /11) which was 263,567 .

The annual CIR was calculated as follows $\left.\frac{\text { (total number of episodes each year) }}{\text { the female population each year }}\right) * 100000$.

The age-standardized incidence rate (ASR)/100,000 PY was calculated using the world standard population according to the WHO statement of 2013 [20]. 
Table 1 Pathogens according to each symptom in women according to WHO

\begin{tabular}{|c|c|c|c|}
\hline Syndromes & & Main pathogens & \\
\hline Genital Ulceration & & -Treponema pallidum (syphilis) & \\
\hline $\begin{array}{c}\text { Pelvic Pain } \\
\text { (and/or ) } \\
\text { Vaginal Discharge }\end{array}$ & -cervicitis* & $\begin{array}{l}\text { - Neisseria gonorrhoeae } \\
\text {-Chlamydia trachomatis }\end{array}$ & $\begin{array}{c}\text {-Curables } \\
\text { STIs }\end{array}$ \\
\hline Vaginal Discharge & -vaginitis** & $\begin{array}{l}\text {-Trichomonas Vaginalis } \\
\text { - Candida albicans } \\
\text { Anaerobic (Gardnerella vaginalis } \\
++ \text { ) }\end{array}$ & $\begin{array}{r}- \text { Non } \\
\text { STIs }\end{array}$ \\
\hline
\end{tabular}

* Discharge of muco-pus through the cervix

* Smelly fluid vaginal discharge

*** Non-specific vaginal discharge (thicker, greenish, smelly)

ST/s Sexually transmitted infections, Non ST/s Non Sexually transmetted infections

${ }^{\dagger}$ : WHO defined chlamydia, gonorrhoea, trichomoniasis and syphilis as curable STIs

The Confidence Intervals (CIs) for CIR and ASR were calculated at a confidence level of $95 \%$.

Data were verified and analyzed using IBM SPSS Statistics version 22.0 software (IBM Corp., Armonk, NY, USA). Categorical variables (age group) were recorded as numbers and percentages. Chi-square test was used to study the association between STIs syndrome and age groups. Linear regression was used to estimate the trends in notified disease according to sex and age group. A $p$-value of $<0.05$ was considered statistically significant.

\section{Ethical considerations}

The study was conducted under Good Clinical Practice conditions and according to ethical standards collections. Data collection and analysis were labelled accordingly to maintain anonymity. The ethics committee of Faculty of medicine of Monastir approved the protocol.

\section{Results}

During 11 years, 40,388 episodes of four female curable STIs were diagnosed by syndromic approach in BHC in Monastir governorate with a mean of 3671 episodes /year. Overall, the crude incidence rate (CIR) was 1393 (95\%CI; 1348-1438) / 100,000 PY being the highest $(3453 / 100,000$ PY) in the $30-39$ age group. ASR was 1328 (95\% Confidence Interval (CI); 1284-1372) /100,000 PY. VD was the most common syndrome (a CIR of 1170/100,000 PY) and specifically vaginosis with a CIR of $907 / 100,000$ PY (Table 2).

In all age groups the VD was the most frequent syndrome $(p<0.001)$ (Fig. 1). For all syndromes, the age group most affected ranged from 20 to $39(p<0.001)$ (Table 3).

The distribution of syndromes by years showed that the highest rate was observed in 2009 with a number of 4996 (CIR =1996/ 100,000 PY). The lowest rate was recorded in 2012 with 2521 episode (939/ 100,000 PY). All syndromes increased over time $(b=139.396 ; r=0.469$; $P<0.001)$. All age groups had a positive trend. The age groups with the highest growth rate were those aged 20 to 39 and 40 to 49 in 11 years with standardized coefficient of $65.27(r=0.39 ; p<0.001)$ and $48.13(r=0.538$; $p<0.001$ ) respectively (Fig. 2).

Episodes of cervicitis, vaginitis, vaginosis, PP and GU increased over time specifically for age group of 20-39 years (Fig. 3).

\section{Discussion}

The incidence rate of STIs episodes among women diagnosed with the syndromic approach was high. Cases increased over time for all age groups and symptoms. VD and especially vaginosis was the most common recorded syndrome. For all syndromes, women aged 20 to 39 were the most affected age group.

Globally, 2012 and 2016 estimates of the incidence of the four curable STIs (chlamydia, gonorrhea, trichomoniasis and syphilis) remain high among women of reproductive age $[1,2,21]$.

World estimates have shown that among the pathogens that cause these four diseases, Trichomonas Vaginalis is the most frequent in women 5.3\% (95\% uncertainty interval UI:4.0-7.2) followed by C. trachomatis 3.8\% (95\%, UI: 3.3-4.5); Neisseria gonorrhoeae 0.9\% (95\% UI: 0.7-1.1) and Treponema pallidum 0.5\% 
Table 2 Crude and age standardized prevalence rates of woman, by age groups and syndromes of sexual transmitted infections diagnosed by syndromic approach in Monastir (2007-2017)

\begin{tabular}{|c|c|c|c|}
\hline & Cases (\%) (11 years) & $\operatorname{CIR}(95 \% \mathrm{Cl})^{a}$ & ASR $(95 \% \mathrm{Cl})^{a}$ \\
\hline Overall & $40,388(100)$ & 1393 (1348-1438) & $1328(1284-1372)$ \\
\hline \multicolumn{4}{|c|}{ Age groups (Years) } \\
\hline $0-4$ & $6(0.0)$ & $2.24(-3-8)$ & \\
\hline $5-14$ & $77(0.2)$ & $15(4-27)$ & \\
\hline $15-19$ & $1060(2.6)$ & 407 (326-488) & \\
\hline $20-29$ & $9986(24.7)$ & $1630(1524-1735)$ & \\
\hline $30-39$ & $15,318(37.9)$ & 3453 (3274-3631) & \\
\hline $40-49$ & $10,268(25.4)$ & 2886 (2703-3049) & \\
\hline$\geq 50$ & $3673(9.1)$ & $700(625-774)$ & \\
\hline \multicolumn{4}{|c|}{ Syndromes } \\
\hline PP & $6126(15.2)$ & $211(193-228)$ & \\
\hline GU & $336(0.8)$ & $11(7-15)$ & \\
\hline VD & $33,926(84.0)$ & $1170(1129-1211)$ & \\
\hline Cervicitis & $1099(2.7)$ & $37(29-45)$ & \\
\hline Vaginitis & $6519(16.1)$ & $224(206-242)$ & \\
\hline Vaginosis & $26,308(65.1)$ & 907 (871-943) & \\
\hline
\end{tabular}

a per 100,000 person year, CIR crude Incidence rate, ASR age standardized rate, 95\%CI 95\% Confidence Interval, PP Pelvic Pain, VD Vaginal Discharge, GU Genital Ulceration

(95\% UI: 0.4-0.6). The same order of pathogens according to their involvement in STIs was also recorded in the East Mediterranean Region (EMR) with a predominance of Trichomonas Vaginalis: 4.7\% (95\% UI: 3.3-6.7) followed by C. trachomatis 3.8\% (95\% UI: 2.6-5.4); gonorrhea $0.7 \%$ (95\% UI: $0.5-1.1$ ) and syphilis $0.7 \%$ (95\% UI: 0.4-1.0) $[1,2,22]$. This frequency order of syndromes was the same as our findings.

The lower rate of GU (syphilis) episodes than in other areas in the East Mediterranean Region may be explained by the fact that in Tunisia, as part of the national perinatal program, screening for syphilis infection is compulsory for the prenuptial examination for both couples and likewise compulsory for pregnant women during the first prenatal visit. This may also explain that the prevalence of infection with syphilis is lower than other pathogens.

In our results, when excluding vaginosis which are in most cases caused by a non sexually transmetted pathogens "Gardnerella vaginalis" [23], we found that vaginitis (mainly caused by Trichomonas Vaginalis) was the most frequent syndrome followed by pelvic pain and cervicitis (mainly caused by C. trachomatis and Neisseria gonorrhea) .

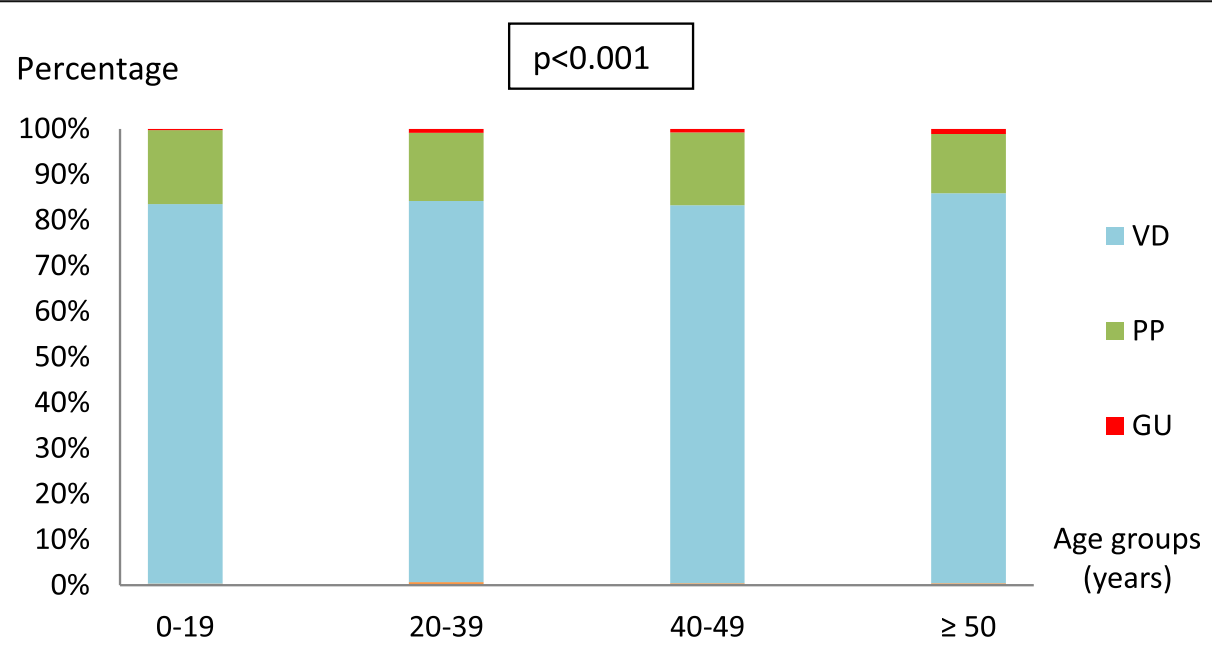

Fig. 1 Distribution of syndromes according to age groups Monastir (2007-2017). PP: Pelvic Pain; VD: Vaginal Discharge; GU: Genital Ulceration 
Table 3 Distribution of STls syndrome by age groups in Monastir (2007-2017)

\begin{tabular}{|c|c|c|c|c|c|c|}
\hline $\begin{array}{l}\text { AGE GROUPS } \\
\text { Syndromes }\end{array}$ & $\begin{array}{l}0-19 \\
\text { n (\%) }\end{array}$ & $\begin{array}{l}20-39 \\
\text { n (\%) }\end{array}$ & $\begin{array}{l}40-49 \\
\text { n (\%) }\end{array}$ & $\begin{array}{l}\geq \mathbf{5 0} \\
\text { n (\%) }\end{array}$ & $\begin{array}{l}\text { Overall } \\
\text { n (\%) }\end{array}$ & $\mathrm{P}^{*}$ \\
\hline PP & $186(3.0)$ & 3818 (62.8) & $1642(26.8)$ & $480(7.8)$ & $6126(100)$ & $<0.001$ \\
\hline GU & $3(0.9)$ & $213(63.4)$ & 80 (23.8) & 40 (11.9) & $336(100)$ & 0.038 \\
\hline VD & $954(2.8)$ & $21,273(62.7)$ & $8546(25.2)$ & $3153(9.3)$ & $33,926(100)$ & $<0.001$ \\
\hline Cervicitis & $31(2.8)$ & 817 (74.3) & $214(19.5)$ & $37(3.4)$ & 1099 (100) & $<0.001$ \\
\hline Vaginitis & $132(2.0)$ & $4467(68.5)$ & 1491 (22.9) & 429 (6.6) & $6519(100)$ & $<0.001$ \\
\hline Vaginosis & 791 (3.0) & $15,989(60.8)$ & 6841 (26) & $2687(10.2)$ & $26,308(100)$ & $<0.001$ \\
\hline
\end{tabular}

PP Pelvic Pain, VD Vaginal Discharge, GU Genital Ulceration, *Chi2-square test

In Tunisia, several studies on the epidemiological characteristics of sexually transmitted infections in women found a high prevalence of VD and the pathogen C. trachomatis in women of reproductive age $[8,12]$. In Morocco, a 1995-2015 study of reported cases of VD showed that the prevalence of $C$. trachomatis was 3.8\%; IC95\%[2.1-6.4] and that of Neisseria gonorrhoeae was 0.37\% IC95\%[0.14-1] [15]. A 2019 meta-analysis found that chlamydia trachomatis infection had the highest mean prevalence $(80.3 \%(95 \% \mathrm{CI}=53.2-97.6 \%))$ among female sex workers in the Middle East and North Africa (MENA) [11] .

In our study, nearly two-thirds of the genital symptoms of STIs were vaginosis (65.1\%) with the highest estimated CIR (907/100,000 PY), compared to other genital symptoms of STIs. A meta-analysis published in 2019 showed that the overall prevalence of bacterial vaginosis in the global population was high, ranging from 23 to $29 \%$ in all regions (Middle East and
North Africa, 25\%; sub-Saharan Africa, 25\%) [24, 25]. This variations in bacterial vaginosis between countries and between ethnic groups within countries are well described [26].

Consistent with our findings, WHO prevalence estimates of the four curable STIs among women have shown an overall positive trend from 2012 to 2016 globally and especially in the EMR [22]. The incidence of STIs has been increasing in Monastir in all age groups. This could be explained by the fact that the beliefs of the population have become more liberal and that sexuality has become a little less taboo, so that the use of care has become less discriminatory over time. On the other hand,the syndromic approach does not allow vaginal sampling, hence the possibility of misdiagnosis, inappropriate prescribing which can also lead to recurrence of episodes of infection and long-term microbial resistance.

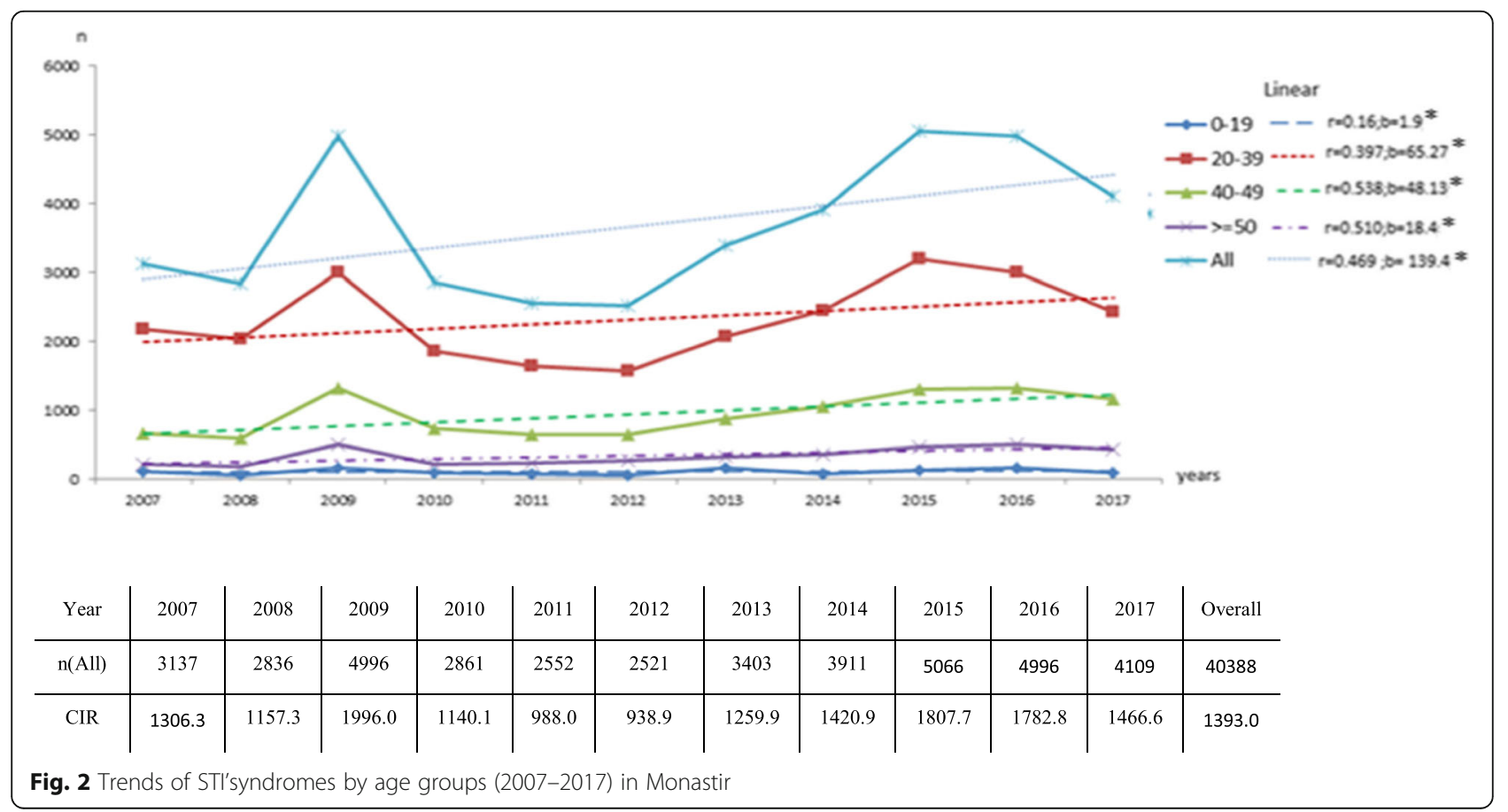




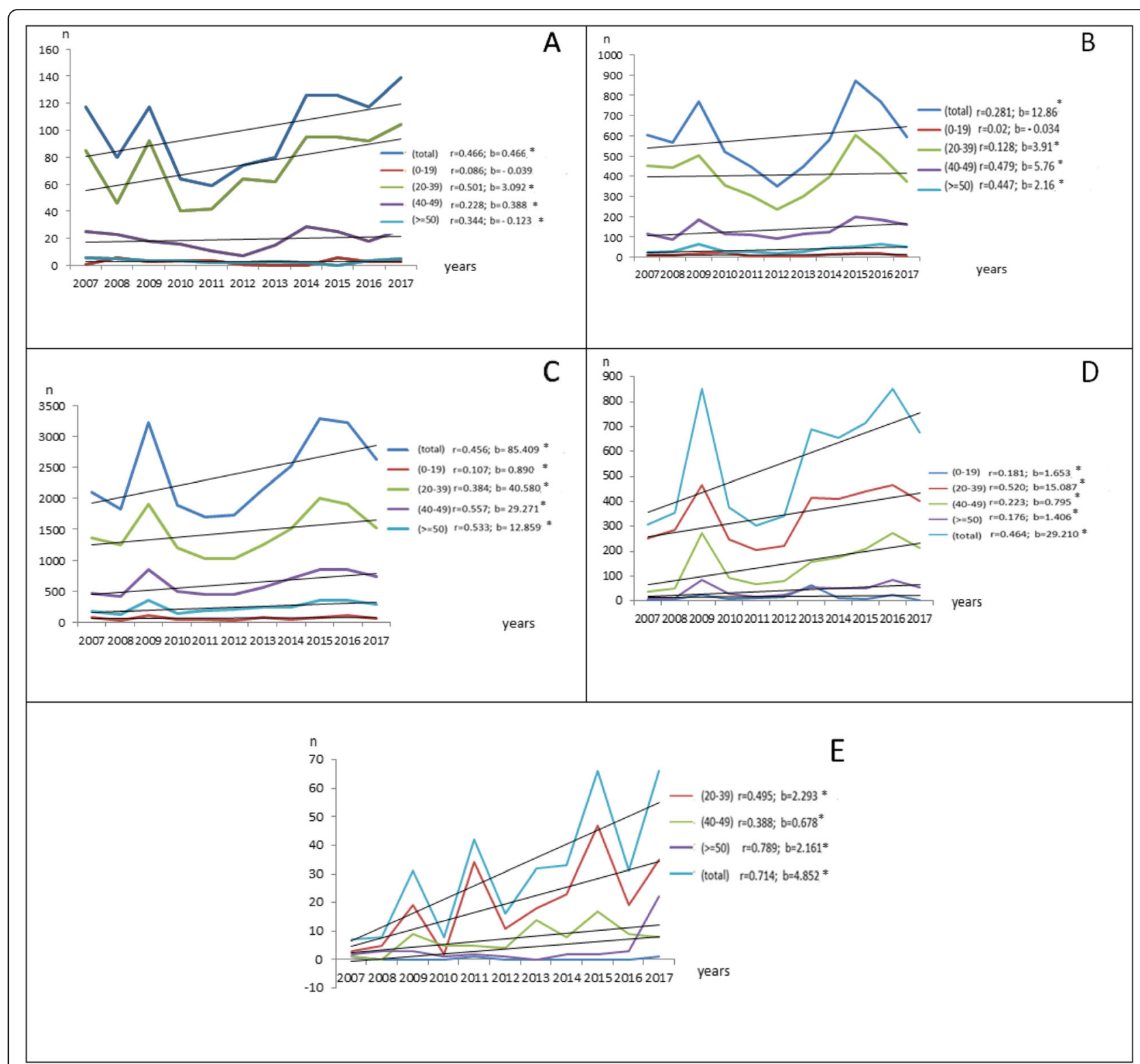

Fig. 3 Distribution of each STI'syndromes by years and age groups (2007-2017) in Monastir. A: cervicitis: for age group of 20-39 years a positive $\operatorname{trend}(r=0.501 ; b=3.092 ; p<0.001)$ was established. B: vaginitis: for age group of 20-39years a positive trend $(r=0.128 ; b=3.91 ; p<0.001)$ was established. C: vaginosis: for age group of 20-39 years a positive trend $(r=0.384 ; b=40.580 ; p<0.001)$ was established. D: pelvic pain: for age group of 20-39 years a positive trend $(r=0.520 ; b=15.087 ; p<0.001)$ was established. E: Genital ulceration: for age group of 20-39years a positive trend $r=0.495 ; b=2.293 ; p<0.001$ was established. ${ }^{*} p<0.001$

In our study, most STI cases were in the 20-39 age group. In fact, it is the sexually active group at high risk of being more susceptible to behavioral exposure to STIs [27-29] and it is the age of reproduction where the search for symptoms of STI infection may be more sought during prenatal visits and pregnancies.

Our study had some limitations. STIs Surveillance at primary health care level was based on syndromic data and not on biological tests. Since each symptom has multiple potential agents, this study based on syndromic data cannot provide accurate statistics on the frequency of STI pathogens. Indeed, according to studies carried out in Tunisia and a prospective observational cohort study in South Africa [3, 8], the diagnosis according to the syndromic approach had low rates of sensitivity and specificity, which suggests an underestimation of the actual rate of STIs in our study due to the fact that asymptomatic cases can only be diagnosed by appropriate laboratory tests.

On the other hand, many cases of VD are not caused by sexually transmitted infections such as cervical ectopy, foreign bodies, retained tampon, vulval 
dermatitis, non-sexually transmitted infection like some bacterial vaginosis and candida infections [30, 31].

Following these results, we recommend several actions. First, improve the knowledge and awareness of people regarding STIs since early age through focusing sexual education efforts in secondary schools. Second, consider periodic routine microbiological etiology surveillance to guide syndromic management of STIs and minimize misdiagnosis. Third, given that STIs and HIV are synergistic $[32,33]$ and that HIV testing in Tunisia is carried out in a few specific basic care centres and that testing is not systematic for all STI consultants(It is an anonymous test and its acceptance by the community remains limited), we suggest to properly screen for contacts and increase the rigour of HIV testing by systematically referring STI cases to the Centre's anonymous and free HIV screening.

\section{Conclusion}

The incidence rate of STIs among women diagnosed with the syndromic approach was high, consistent with the global evidence. It showed a positive trend over 11 years for all age groups and syndromes. VD was the most common recorded syndrome. For all syndromes, women aged 20 to 39 were the most affected age group. To achieve the World Health Organization goal of ending STIs epidemics by 2030, several measures should be reinforced in low and middle-income countries such as strengthening the STI surveillance system, additional preventive interventions, prompt identification, correct treatment, and partner tracing to stop the spread of these infections.

\footnotetext{
Abbreviations

ASR: Age-Standardized Incidence Rate; BHC: Basic Health Centers; CIR: Crude Incidence Rate; EMR: East Mediterranean Region; GU: Genital Ulceration; HICs: High-Income Countries; HIV: Human Immunodeficiency Virus; LMICs: Low- and Middle-Income Countries; MENA: Middle East and North Africa; PP: Pelvic Pain; STls: Sexually Transmitted Infections; VD: Vaginal Discharge; WHO: World Health Organization
}

\section{Supplementary Information}

The online version contains supplementary material available at https://doi. org/10.1186/s12889-021-11647-2.

Additional file 1: Appendix 1. The WHO syndromic approach summarized in flowcharts (clinical algorithm)

\section{Acknowledgments}

The authors thank the team of the regional direction of primary health, department of Epidemiology and Preventive Medicine at the university hospital of Monastir. Authors offer this paper to our eminent Professor Soltani Mohamed.

\section{Authors' contributions}

WD: Conceptualization, Formal analysis, Methodology,Writing - original draft. ASB and IZ: design of the work Formal analysis, Methodology, Super- vision and substantively revised the draft. MK,CBN,MBF,HA and MM: Formal analysis, interpretation of data and draft revision. SSG: data collection and verification.
All authors agreed to be personally accountable for the author's own contributions, have read and approved the manuscript.

Funding

This study received no financial support.

\section{Availability of data and materials}

The data that support the findings of this study are available from the regional direction of primary health of Monastir but restrictions apply to the availability of these data, which were used under license for the current study, and so are not publicly available. Data are however available from the authors upon reasonable request and with permission of the regional direction of primary health of Monastir.

\section{Declarations}

Ethics approval and consent to participate

The study was approved by the Ethical Committee of faculty of medicine (Monastir). As this was a retrospective study and the anonymity was respected, the need for consent deemed unnecessary according to ethical Committee of faculty of medicine (Monastir). Access to data was allowed after administrative permission of the regional health directorate in the governorate of Monastir and after ethics committee approval.

Consent for publication

Not Applicable.

\section{Competing interests}

The authors declare that they have no competing interests.

\section{Author details}

${ }^{1}$ Department of Epidemiology and Preventive Medicine, University of Monastir, Monastir, Tunisia. ${ }^{2}$ The Regional Direction of Primary Health of Monastir, Monastir, Tunisia. ${ }^{3}$ Microbiology Laboratory, Monastir, Tunisia.

Received: 3 September 2020 Accepted: 23 August 2021

Published online: 06 September 2021

\section{References}

1. Newman L, Rowley J, Vander Hoorn S, Wijesooriya NS, Unemo M, Low N, et al. Global estimates of the prevalence and incidence of four curable sexually transmitted infections in 2012 based on systematic review and global reporting. PLoS One. 2015;10(12):e0143304. https://doi.org/10.1371/ journal.pone.0143304.

2. GBD 2016 Disease and Injury Incidence and Prevalence Collaborators. Global, regional, and national incidence, prevalence, and years lived with disability for 328 diseases and injuries for 195 countries, 1990-2016: a systematic analysis for the Global Burden of Disease Study 2016. Lancet Lond Engl. 2017;390(10100):1211-59.

3. Jennings LK, Krywko DM. Pelvic inflammatory disease. In: StatPearls. Treasure Island (FL): StatPearls Publishing; 2021. http://www.ncbi.nlm.nih.gov/books/ NBK499959/

4. Tsehay B, Afework M. Precancerous lesions of the cervix and its determinants among Ethiopian women: systematic review and metaanalysis. PLoS One. 2020;15(10):e0240353. https://doi.org/10.1371/journal. pone.0240353.

5. Karim S, Souho T, Benlemlih M, Bennani B. Cervical Cancer induction enhancement potential of Chlamydia trachomatis: a systematic review. Curr Microbiol. 2018:75(12):1667-74. https://doi.org/10.1007/s00284-018-1439-7.

6. $\mathrm{WHO} \mid$ Global health sector strategy on Sexually Transmitted Infections, 2016-2021 . WHO. http://www.who.int/reproductivehealth/publications/rtis/ ghss-stis/en/

7. WHO | Global strategy for the prevention and control of sexually transmitted infections: 2006-2015. WHO. http://www.who.int/ reproductivehealth/publications/rtis/9789241563475/en/

8. Zribi M, Mansour KB, Abid F, Masmoudi A, Fendri C. Syndromic approach to sexually transmitted infections in Tunisian women: bacteriological validation. Int J STD AIDS. 2008;19(2):112-4. https://doi.org/10.1258/ijsa.2007. 007140

9. Dickson C, Arnason T, Friedman DS, Metz G, Grimshaw JM. A systematic review and appraisal of the quality of practice guidelines for the 
management of Neisseria gonorrhoeae infections. Sex Transm Infect. 2017 93(7):487-92. https://doi.org/10.1136/sextrans-2016-052939.

10. Bourouache M, Mimouni R, Nejmeddine M, Chadli S, Benlmeliani F, Sardi J, et al. The prevalence of syphilis in HIV-seropositive patients: a retrospective study at the regional hospital in Agadir, Morocco. Pan Afr Med J. 2019;33 https://www.ncbi.nlm.nih.gov/pmc/articles/PMC6814908/.

11. Chemaitelly H, Weiss HA, Smolak A, Majed E, Abu-Raddad L. Epidemiology of Treponema pallidum, Chlamydia trachomatis, Neisseria gonorrhoeae, Trichomonas vaginalis, and herpes simplex virus type 2 among female sex workers in the Middle East and North Africa: systematic review and metaanalytics. J Glob Health. 9(2) https://www.ncbi.nlm.nih.gov/pmc/articles/ PMC6642815/.

12. Znazen A, Frikha-Gargouri O, Berrajah L, Bellalouna S, Hakim H, Gueddana N, et al. Sexually transmitted infections among female sex workers in Tunisia: high prevalence of Chlamydia trachomatis. Sex Transm Infect. 2010;86(7): 500-5. https://doi.org/10.1136/sti.2010.042770.

13. Bchir A, Jemni L, Saadi M, Milovanovic A, Brahim H, Catalan F. Markers of sexually transmitted diseases in prostitutes in Central Tunisia. Genitourin Med. 1988;64(6):396-7.

14. Bennani A, El-Kettani A, Hançali A, El-Rhilani H, Alami K, Youbi M, et al. The prevalence and incidence of active syphilis in women in Morocco, 19952016: Model-based estimation and implications for STI surveillance. PLoS One. 2017;12(8) https://www.ncbi.nlm.nih.gov/pmc/articles/PMC5570350/.

15. El-Kettani A, Mahiané G, Bennani A, Abu-Raddad L, Smolak A, Rowley J, et al. Trends in adult Chlamydia and gonorrhea prevalence, incidence and urethral discharge case reporting in Morocco over 1995-2015-estimates using the Spectrum-sexually transmitted infection model. Sex Transm Dis. 2017;44(9):557-64. https://doi.org/10.1097/OLQ.0000000000000647.

16. Recencement. INS. http://census.ins.tn/en/recensement

17. Carte sanitaire - Ministère de la santé publique. http://www.santetunisie.rns. tn/fr/sante-en-tunisie/la-sante-scolaire-et-universitaire/carte-sanitaire

18. World Health Organization, éditeur. Guidelines for the management of sexually transmitted infections. Geneva: World Health Organization; 2003. p. 91.

19. Portail de données de la Tunisie, Analyse de Données http://dataportal.ins. tn/fr/DataAnalysis?8xPhnNxdAku94ZDqKTYVfw

20. World (WHO 2000-2025) Standard - Standard Populations - SEER Datasets. https://seer.cancer.gov/stdpopulations/world.who.html

21. Chesson HW, Mayaud P, Aral SO. Sexually transmitted infections: impact and cost-effectiveness of prevention. In: Holmes KK, Bertozzi S, bloom BR, Jha P, éditeurs. Major infectious diseases. 3rd éd. Washington (DC): The International Bank for Reconstruction and Development / The World Bank; 2017. http://www.ncbi.nlm.nih.gov/books/NBK525195/

22. Rowley J, Vander Hoorn S, Korenromp E, Low N, Unemo M, Abu-Raddad L, et al. Chlamydia, gonorrhoea, trichomoniasis and syphilis: global prevalence and incidence estimates, 2016. Bull World Health Organ. 2019;97(8):548$562 P$.

23. Morris MC, Rogers PA, Kinghorn GR. Is bacterial vaginosis a sexually transmitted infection? Sex Transm Infect. 2001;77(1):63-8. https://doi.org/1 0.1136/sti.77.1.63.

24. Javed A, Parvaiz F, Manzoor S. Bacterial vaginosis: An insight into the prevalence, alternative treatments regimen and it's associated resistance patterns. Microb Pathog. 2019;127:21-30.

25. Peebles K, Velloza J, Balkus JE, McClelland RS, Barnabas RV. High global burden and costs of bacterial vaginosis: a systematic review and metaanalysis. Sex Transm Dis. 2019;46(5):304-11.

26. Kenyon C, Colebunders R, Crucitti T. The global epidemiology of bacterial vaginosis: a systematic review. Am J Obstet Gynecol. 2013;209(6):505-23. https://doi.org/10.1016/j.jojog.2013.05.006.

27. Pringle J, Mills KL, McAteer J, Jepson R, Hogg E, Anand N, et al. The physiology of adolescent sexual behaviour: A systematic review. Cogent Soc Sci. 2017;3(1):1368858

28. Ranganathan M, MacPhail C, Pettifor A, Kahn K, Khoza N, Twine R, et al. Young women's perceptions of transactional sex and sexual agency: a qualitative study in the context of rural South Africa. BMC Public Health. 2017;17 https://www.ncbi.nlm.nih.gov/pmc/articles/PMC5568133/.

29. Chatterji M, Murray N, London D, Anglewicz P. The factors influencing transactional sex among young men and women in 12 sub-Saharan African countries. Soc Biol Spring-Summer. 2005;52(1-2):56-72.

30. Spence D, Melville C. Vaginal discharge. BMJ. 2007:335(7630):1147-51.
31. Maleb A, Frikh M, Lahlou YB, Belefquih B, Lemnouer A, Elouennass M. Écoulements vaginaux d'origine infectieuse chez la femme adulte à l'hôpital militaire d'instruction Mohammed V de Rabat (Maroc) : étude de 412 cas. Rev Sage Femme. 2018;17(3):122-6.

32. Kabapy AF, Shatat HZ, Abd El-Wahab EW. Attributes of HIV infection over decades (1982-2018): a systematic review and meta-analysis. Transbound Emerg Dis. 2020;67(6):2372-88. https://doi.org/10.1111/tbed.13621.

33. Kilburn K, Ranganathan M, Stoner MCD, Hughes JP, MacPhail C, Agyei Y, et al. Transactional sex and incident HIV infection in a cohort of young women from rural South Africa. AIDS Lond Engl. 2018;32(12):1669-77.

\section{Publisher's Note}

Springer Nature remains neutral with regard to jurisdictional claims in published maps and institutional affiliations.
Ready to submit your research? Choose BMC and benefit from:

- fast, convenient online submission

- thorough peer review by experienced researchers in your field

- rapid publication on acceptance

- support for research data, including large and complex data types

- gold Open Access which fosters wider collaboration and increased citations

- maximum visibility for your research: over $100 \mathrm{M}$ website views per year

At BMC, research is always in progress.

Learn more biomedcentral.com/submissions 